\title{
THE EFFECT OF WATER STRESS ON RADIATION INTERCEPTION, RADIATION USE EFFICIENCY AND WATER USE EFFICIENCY OF MAIZE IN A TROPICAL CLIMATE
}

\author{
Geneille E. GREAVES ${ }^{I}, Y u$-Min WANG ${ }^{2 *}$ \\ ${ }^{I}$ National Pingtung University of Science and Technology, Department of Tropical Agriculture and \\ International Cooperation, Pingtung, TAIWAN (R.O.C) \\ ${ }^{2}$ National Pingtung University of Science and Technology, Department of Civil Engineering, Pingtung, \\ TAIWAN (R.O.C) \\ *Corresponding author: wangym@mail.npust.edu.tw
}

Received: 02.12.2016

\begin{abstract}
This study was conducted to investigate the effect of deficit irrigation on radiation capture, radiation use efficiency (RUE) and water use efficiency (WUE) in maize production, and to assess how these factors impact biomass production in water stress environments. Five irrigation levels were investigated: a full irrigation treatment with a water depth of $60 \mathrm{~mm}\left(I_{1}\right)$, and four deficit irrigation treatments with depths of $50\left(I_{2}\right), 40\left(I_{3}\right)$, $30\left(I_{4}\right)$ and $20 \mathrm{~mm}\left(I_{5}\right)$. Crop water stress index values indicated treatments $I_{2}$ and $I_{3}$ caused mild water stress while $I_{4}$ and $I_{5}$ caused severe stress. Water deficits significantly $(p<0.05)$ reduced leaf area index compared to full irrigation. The reduction in biomass for $I_{2}$ to $I_{5}$ ranged between 7 and $43 \%$ relative to $I_{1}$. In $I_{1}$, the RUE was $3.46 \mathrm{~g} \mathrm{MJ}^{-1}$, while mild and severe water stress significantly reduced it to 3.11 and $2.69 \mathrm{~g} \mathrm{MJ}^{-1}$, respectively. A reduction in both intercepted photosynthetically active radiation and RUE contributed significantly to biomass reduction. Mild and severe water stress improved the WUE within range of 2 and $25 \%$ and 10 and $34 \%$, respectively. The results suggest that in mild water stress environments, high RUE aids in minimizing production losses, and in cases of severe water stress, the reduced ability to capture and utilize radiation is compensated by improving the WUE.
\end{abstract}

Keywords: biomass, crop water stress index, deficit irrigation, maize, photosynthetically active radiation.

\section{INTRODUCTION}

Increasing global pressure to maintain food security and environmental integrity, under the constraints of increasing food and water demands, an evolving economy and decreasing water availability for irrigation dictates that crop production improve per unit of water consumed (Spiertz, 2012). As such, irrigation management strategies that mitigate water wasted in crop production while minimizing yield losses have an integral role to play in sustainable agricultural development. Deficit irrigation (DI), defined as the intentional under-irrigation of crops, has been identified as a water management strategy that can improve water use in irrigated agricultural production (Klocke et al., 2004). However, this management practice can expose plants to abiotic stress that often results in plants modifying specific mechanisms and thus leading to a reduction in productivity (Akcay and Dagdelen, 2016). Thus, as crop productivity is directly related to plants ability to capture resources, such as water and light, and the efficiency with which they convert these physical resources into biological materials (Yi et al., 2010), a practical technique for quantifying plant response to its growing environment involves relating its dry matter production to either the amount of radiation captured or water transpired. These processes are often categorized as either 'solar engine' or 'water engine' (Steduto and Albrizio, 2005; Mwale et al., 2007).

The solar growth-engine quantifies crop growth as a function of the radiation captured and used. Crop biomass production depends on total solar radiation, the fraction of this radiation that is intercepted by the crop canopy and the efficiency by which intercepted radiation is converted into biomass (Lindquist et al., 2005; Teixeira et al., 2014). The parameter used to quantify this relation, defined as the amount of dry biomass produced per unit intercepted photosynthetically active radiation $\left(\mathrm{PAR}_{\mathrm{i}}\right)$, is the radiation use efficiency (RUE). Traditionally, the RUE is estimated by regressing cumulative biomass on radiation intercepted because of the strong linear relationship between these variables (Sinclair and Muchow, 1999). However, it has been criticized because of its dependence on cumulative intercepted energy which has logical and arithmetic weaknesses (Demetriades-Shaw et al., 1994), and because its consistency mainly ascribes to optimal growing 
conditions (Albrizio and Steduto, 2005). Alternatively, RUE can be quantified by the short-interval crop growth rate (CGR) method, determined as the biomass increase between two consecutive harvests and the $\mathrm{PAR}_{\mathrm{i}}$ during that period (Lindquist et al., 2005; Confalone et al., 2010). These authors highlighted that this method is the least bias because CGR values are independent.

One of the most influential factors to agricultural production systems is the soil moisture environment during the growing season, and in non-limiting environments the water-driven growth engine generally dominates crop growth and productivity. However, as water becomes a limiting factor, crop growth is influenced by both the water-driven and solar-driven growth engine as both the fraction of intercepted radiation and RUE can be reduced under drought (Mwale et al., 2007). Under water stress conditions, plants may modify their water extraction pattern from the soil, minimize water transpired by closing their stomata and reduce the diffusion of $\mathrm{CO}_{2}$ into the leaves (Mwale et al., 2007; Yi et al., 2010). Water stress also results in reduced green leaf area index (LAI) which progressively leads to reduced $P_{A} R_{i}$ and RUE (O'Connell et al., 2004). Water use efficiency (WUE) defined in terms of the relationship between above ground biomass and cumulative transpiration is often used to quantify the influence of soil moisture on crop growth owing to the conservative link between biomass and transpiration (Steduto and Albrizio, 2005). This method of examining water productivity intrinsically reflects the genetic response of the crop and is a direct reflection of the efficiency of water use at the plant level (Vadez et al., 2014).

Maize is the most widely produced crop in the world. Owing to the diversification of its uses, its production facilitate in the improvement of a country's food selfsufficiency and food security. The production of maize in Taiwan has decreased considerably over the last decades owing mainly to an expansion in rice production (Perng, 2013). Thus, reviving the maize industry is vital in the efforts towards creating a more diverse and resilient agriculture sector. In Taiwan, the main growing period for maize usually occurs during the winter season which is characterized by low precipitation. Consequently, irrigation is often used as a supplemental water source. However, decreasing water availability for irrigation amid a water intensive rice industry, Taiwan's main crop, heightens the need to identify sustainable water management strategies to ensure successful revival and planned expansion of maize production. Implementing a feasible DI management strategy requires rigorous exploration, especially given that relatively low solar radiation and temperatures are also features of the main cropping season. Payero et al. (2006) and Farré and Faci (2009) reported that the feasibility of this strategy is subject to specific/localized environments and highlighted that this water management strategy might not be suitable under all climatic environments. Factors affecting the feasibility can be attributed to the capture and use of essential production resources.

The objectives of this study were; (i) to investigate the effect of water deficits on radiation capture, RUE and WUE of maize in southern Taiwan tropical environment; and (ii) to examine whether the high productivity of maize subject to feasible DI strategies is attributable to the ability in intercepting solar radiation during the growing season, to high RUE, or to a combination of both factors.

\section{MATERIALS AND METHODS}

\section{Site characteristics, growing environment and agronomic details}

Field experiments were conducted during the winter cropping season from November to March 2014 to $2015(2014 / 15)$ and 2015 to $2016(2015 / 16)$ at the irrigation experimental site of National Pingtung University of Science and Technology, Southern Taiwan $\left(22.65^{\circ} \mathrm{N}\right.$ : $34.95^{\circ} \mathrm{E}: 71 \mathrm{~m}$ above sea level). The soil at the experimental site is classified as loamy (27\% sand; $24 \%$ clay) with a bulk density of $1.4 \mathrm{~g} / \mathrm{cm}^{3}$. The average volumetric water content for a $1 \mathrm{~m}$ soil profile depth at saturation, field capacity and permanent wilting point are 42.9, 30.5 and 15\%, respectively. The November to March growing period is one of the main cropping seasons for maize in this location as summer months, which have a warmer and more conducive temperature for maize production, coincide with the typhoon season which increases farmer's risk in crop production. The climate for the study area is classified as tropical wet and dry with extreme spatial and temporal rainfall distribution; more than $80 \%$ of the rainfall occurs in the wet period from May to October and most of the rain is concentrated in typhoon events. Associative dry spells and lack of rainfall are thus features of this cropping season.

The 2014/15 cropping season was drier than 2015/16 with cumulative rainfall of $40 \mathrm{~mm}$ compared to $214 \mathrm{~mm}$. In particular, January was wetter during the 2015/16 season with a total rainfall of $141.5 \mathrm{~mm}$ (Fig. 1). The rainfall recorded during the 2015/16 season was atypical to that observed for the study location; total long-term (15 years) rainfall during the cropping period is $65.4 \mathrm{~mm}$. Seasonal mean incident solar radiation was approximately 14.9 and 13.9 $\mathrm{MJ} \mathrm{m}^{-2} \mathrm{~d}^{-1}$ in 2014/15 and 2015/16, respectively. The average air temperature during both seasons was about $20^{\circ} \mathrm{C}$. Over the two seasons, the mean daily maximum temperature ranged from 11 to $32{ }^{\circ} \mathrm{C}$, while the mean daily minimum temperature ranged from 5 to $22{ }^{\circ} \mathrm{C}$. Seasonal variation in weather conditions for both cropping seasons is depicted in Fig. 1. 

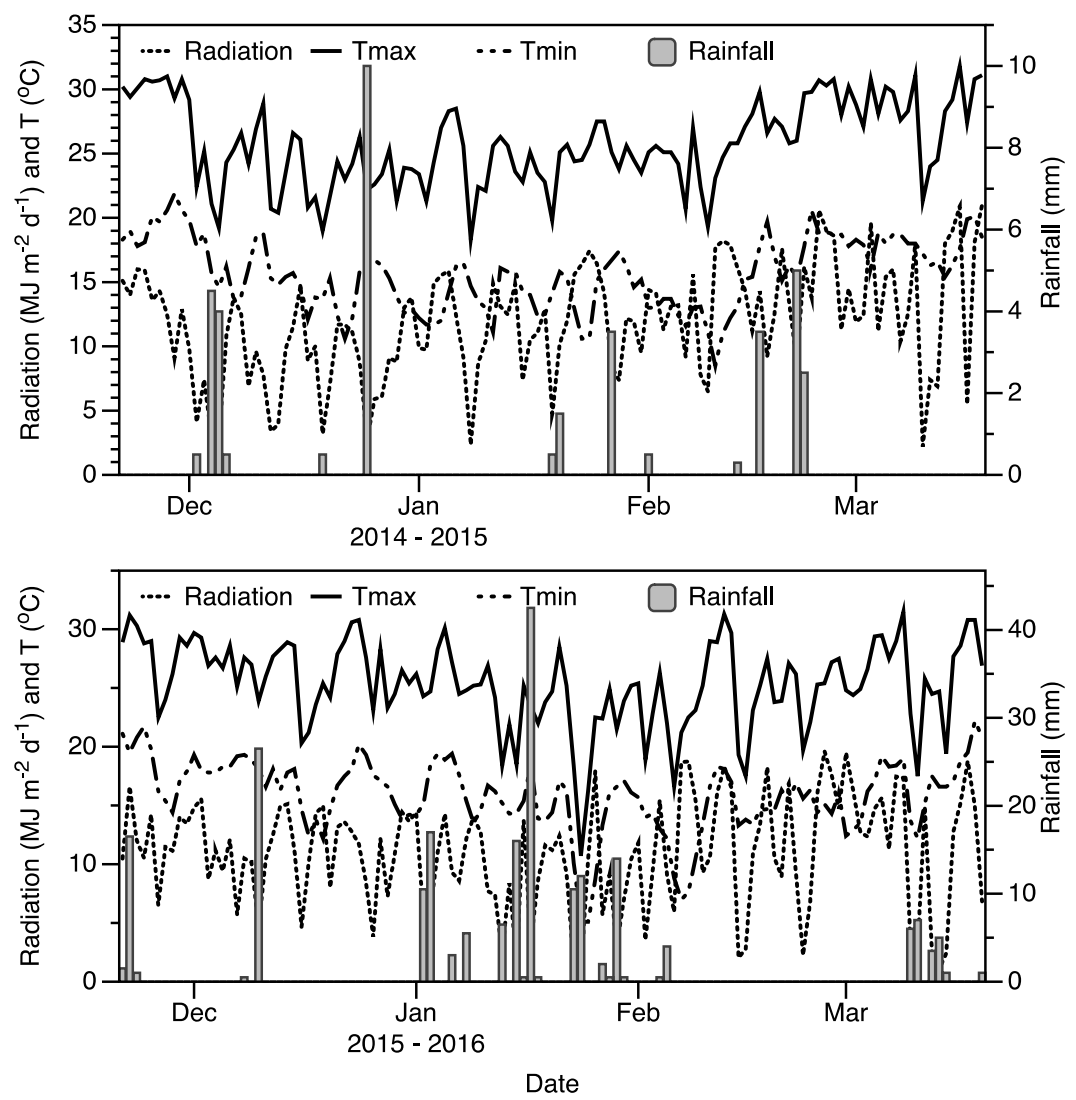

Figure 1. Daily variation in solar radiation, maximum air temperature (Tmax), minimum air temperature (Tmin) and rainfall over the two growing seasons.

In 2014 maize was planted on $22^{\text {nd }}$ November, while for the 2015 season planting was done on $21^{\text {st }}$ November. During both seasons crops were subjected to the same field management practices. Treated seeds were sown in holes $0.05 \mathrm{~m}$ deep in well-leveled basins of size $10 \mathrm{~m}^{2}$ at a plant density of 8.3 plants $/ \mathrm{m}^{2}$. Soil levees $0.30 \mathrm{~m}$ high and $1 \mathrm{~m}$ wide were used to create a buffer zone between plots. Fertilizer $\left(275,125\right.$, and $125 \mathrm{~kg} / \mathrm{ha}$ of $\mathrm{N}, \mathrm{P}_{2} \mathrm{O}_{5}$ and $\left.\mathrm{K}_{2} \mathrm{O}\right)$ was applied to the field when needed to prevent nutrient stress. Insects and diseases were rigorously controlled and plots were hand weeded when necessary so that there was no competition for light, nutrients or water. Crop phenology was constantly monitored during the growing season and the different phenological stages were subsequently recorded according to Ritchie et al. (1992). According to Ritchie et al. (1992) classification, the main growth stage used in the study for observations and measurements was the vegetative six leaf stage (V6) and ten leaf stage (V10), anthesis, and the reproductive milk stage (R3) and physiological maturity (R6).

\section{Irrigation treatments and soil moisture monitoring}

In both seasons there were 5 irrigation treatments, replicated 3 times, arranged in a completely randomized block design. Treatments were differentiated from each other based only on the amount of irrigated water applied, irrespective of the phenological growth stage. The rationale for this was to maintain a consistent irrigation schedule based on soil moisture availability. Irrigation depth and time were determined based on the maximum allowable depletion of total available soil water in the soil profile (Panda et al., 2004). Treatments included a full irrigation treatment (FIT) and four deficit treatments. The FIT water application depth was calculated as (Panda et al., 2004):

$$
V_{d}=\frac{A D(\%)(F C \text { WP }) R_{z} A}{100}
$$

where $V_{d}$ is the volume of irrigation water $\left(\mathrm{m}^{3}\right), A D$ is the allowed depletion, FC is the field capacity $\left(\mathrm{m}^{3} \mathrm{~m}^{-3}\right)$, WP is the permanent wilting point $\left(\mathrm{m}^{3} \mathrm{~m}^{-3}\right), \mathrm{R}_{\mathrm{z}}$ is the effective rooting depth (m), and A is the surface area of the plot $\left(\mathrm{m}^{2}\right)$. Considering an effective root zone of $1 \mathrm{~m}$ and $\mathrm{AD}$ as $40 \%$ (Djaman et al., 2013), the depth of water application estimated for the FIT was $60 \mathrm{~mm}\left(\mathrm{I}_{1}\right)$. Irrigation levels assigned to deficit treatments decreased in increments of $10 \mathrm{~mm}$; treatments $\mathrm{I}_{2}, \mathrm{I}_{3}, \mathrm{I}_{4}$, and $\mathrm{I}_{5}$ respectively received 50,40,30 and $20 \mathrm{~mm}$ of water at each irrigation event. The treatments were irrigated by flooding each plot with water from pipes and the use of water meters. During early vegetative growth (emergence to maize five leaf stage) all treatments received approximately $75 \mathrm{~mm}$ of water. This was necessary to promote robust root development and to establish plants (Candogan et al., 2013; Kuscu et al., 2013). Thus, irrigation treatment management began from the V6 growth stage and irrigation was initiated for all treatments whenever the soil moisture in treatment $I_{1}$ reached the $40 \%$ moisture depletion level. This depletion criterion was 
determined by constantly monitoring the soil water content (SWC). The percentage depletion of available soil water in the effective root zone was estimated as (Igbadun et al., 2008):

$$
\operatorname{depletion}(\%)=100 \frac{1}{n}{ }_{1}^{n} \frac{F C_{i} \quad i}{F C_{i} W P}
$$

where $\mathrm{n}$ is the number of sub-divisions of the effective rooting depth, $\mathrm{FC}_{\mathrm{i}}$ is the soil moisture at field capacity for $\mathrm{i}^{\text {th }}$ layer, $\theta_{\mathrm{i}}$ is the soil moisture in $\mathrm{i}^{\text {th }}$ layer, and WP is the soil moisture at permanent wilting point. $\theta$ was monitored daily using soil moisture sensors, EnviroScan system (Sentek technologies, Australia), connected to an automatic datalogger. Sensors were installed in between two plants on the same row through PVC access tubes in two replicate per treatment. The SWC were measured at $0.10 \mathrm{~m}$ intervals to a depth of $1 \mathrm{~m}$. Soil water depletion (SWD) was determined as the difference between volumetric moisture content at field capacity for that depth and volumetric moisture content on the day of irrigation (before water was applied). The total SWD for the rooting depth of $1 \mathrm{~m}$ was taken as the summation of the depletion in all of the sampled layers (Yi et al., 2010).

\section{Crop growth and development}

In both seasons, four plants in at-least two replicates were randomly selected and clipped at the soil surface to assess biomass accumulation throughout the season. To maintain a level of consistency, this was done at the above-mentioned growth stages in each year. Total above ground biomass was determined after drying the samples at $70{ }^{\circ} \mathrm{C}$ until constant weight was attained. At harvest, samples were taken from all plots and subjected to the same handling to determine the final accumulation of biomass. Eight randomly selected plants per plot were tagged to monitor leaf area index (LAI) throughout the growing season. The LAI was calculated as the product of the manually measured leaf area (maximal length $\mathrm{x}$ width) of each leaf, by the shape factor $(k=0.75)$, by the plant density (Yi et al., 2010).

\section{Quantification of crop water stress and crop evapotranspiration}

When a crop goes through water stress the functional response of stomata closure results in the relative transpiration rate decreasing. Thus, as soil water becomes limiting the actual crop evapotranspiration $\left(\mathrm{ET}_{\mathrm{c}}\right)$ rate falls below the reference (potential) evapotranspiration rate $\left(\mathrm{ET}_{\mathrm{o}}\right)$ (Jackson, 1982). Consequently, the ratio of actual to reference ET is well established as an index of crop water status, and the crop water stress index $\left(\mathrm{CWSI}=1-\mathrm{ET}_{\mathrm{c}} / \mathrm{ET}_{\mathrm{o}}\right)$ has been identified as a valuable tool for monitoring and quantifying water stress (Alderfasi and Nielsen, 2001; Irmak et al., 2002). CWSI varies from 0 to 1 , with 0 representing no water stress as the plant transpires at the maximum rate, and 1 signifying maximum stress as the plant has no transpiration loss (Idso, 1982).

Daily $\mathrm{ET}_{\mathrm{o}}$ was calculated from weather data using FAO-56 standardized Penman-Moneith equation
(Allen et al., 1998). The $\mathrm{ET}_{\mathrm{c}}$ of each treatment was calculated using the soil water balance method (Kuscu et al., 2013):

$$
E T_{c}=P+I \quad D \quad R \pm W
$$

where $\mathrm{P}$ indicates rainfall $(\mathrm{mm}), \mathrm{I}$ is the irrigation $(\mathrm{mm}), \mathrm{D}$ is downward drainage out of the root zone $(\mathrm{mm})$, $\mathrm{R}$ is the surface runoff ( $\mathrm{mm}$ ), and $\Delta \mathrm{W}$ is the change in the water content of the soil profile $(\mathrm{mm})$. D was consider to be equal to zero as gravimetric sampling beyond the $1 \mathrm{~m}$ effective root zone indicated that changes in the SWC was very small. Gravimetric sampling was done for a maximum depth of $1.6 \mathrm{~m}$ (from $1 \mathrm{~m}$ at $0.2 \mathrm{~m}$ intervals) periodically. $\mathrm{R}$ was assumed zero because irrigation water application was controlled and the experimental plots were surrounded by $1 \mathrm{~m}$ wide levees around its perimeter with basins meticulously prepared to be level. $\Delta \mathrm{W}$ was estimated from measured soil moisture data obtained via the EnviroScan system on a daily time step. Growing season $\mathrm{ET}_{\mathrm{c}}$ was calculated as the summation of daily $\mathrm{ET}_{\mathrm{c}}$.

\section{Intercepted solar radiation and resource use efficiencies}

In this study it was assumed that $50 \%$ of the total incident solar radiation was PAR and the amount of PAR intercepted by the plant canopy $\left(\mathrm{PAR}_{\mathrm{i}}\right)$ was computed using the following exponential function (Yi et al., 2010):

$$
P A R_{q}=0.5 R\left(1 e^{k L A l}\right)
$$

where $\mathrm{R}$ is the total solar radiation $\left(\mathrm{MJ} \mathrm{m} \mathrm{m}^{-2} \mathrm{~d}^{-1}\right)$ and $\mathrm{k}$ is the light extinction coefficient which equals 0.65 for maize (Yi et al., 2010).

Maize RUE was estimated using the crop growth rate method (CGR); the increase in crop dry matter between two consecutive sampling dates was regressed on the quantity of $\mathrm{PAR}_{\mathrm{i}}$ between those dates for each treatment. The slope of this regression line is the RUE. CGR was estimated by the plant dry weight method (Rahman and Hossain, 2011):

$$
C G R=\frac{W_{2} W_{1}}{t_{2} t_{1}}
$$

where $\mathrm{W}_{1}$ and $\mathrm{W}_{2}$ indicates plant dry weight at time $\mathrm{t}_{1}$ and $t_{2}$, respectively. If statistic testing resulted in insignificant differences among treatments, all the data was pooled to obtain a single RUE estimate for the study area.

The WUE for each treatment was calculated as the slope of the regression line of total biomass on accumulated plant transpiration $\left(\mathrm{W}_{\mathrm{t}}\right)$. $\mathrm{W}_{\mathrm{t}}$ was calculated as the difference between $\mathrm{ET}_{\mathrm{c}}$ and actual evaporation from the cropped area of each treatment $\left(\mathrm{E}_{\mathrm{cs}}\right)$ (Mwale et al., 2007). $\mathrm{E}_{\mathrm{cs}}$ was estimated as (Igbadun et al., 2008):

$$
E_{C S}=E_{S} \quad e^{k L A l}
$$

where $E_{\mathrm{cs}}$ is the actual evaporation from the soil of the cropped plots $(\mathrm{mm}), \mathrm{E}_{\mathrm{s}}$ is the evaporation $(\mathrm{mm})$ from 
uncropped soil, and other terms are as previously defined. $E_{\mathrm{s}}$ was estimated from bare plots of approximately the same dimensions as the experimental plots. These plots were irrigated at the same time as the cropped plots and with the same amount of water as the respective treatments. $\mathrm{E}_{\mathrm{s}}$ was estimated as the difference between measured SWC obtained by the gravimetric method, taken within 3 to 5 day intervals, for a profile depth of $0-15 \mathrm{~cm}$ (Igbadun et al., 2008).

The losses in biomass attributable to the reduction of different resources were estimated using the simple path model described by Earl and Davis (2003). Biomass losses (L) were investigated as a component of reduced $\mathrm{PAR}_{\mathrm{i}}$ and RUE and calculated using the following respective equations (Earl and Davis, 2003):

$$
\begin{aligned}
& L_{P A R i}=B_{C} \times\left(\begin{array}{ll}
1 & \frac{P A R i_{S}}{P A R i_{C}}
\end{array}\right) \\
& L_{R U E}=\left(\begin{array}{ll}
B_{C} & L_{P A R i}
\end{array}\right) \times\left(\begin{array}{ll}
1 & \frac{R U E_{S}}{R U E_{C}}
\end{array}\right)
\end{aligned}
$$

where $\mathrm{B}_{\mathrm{C}}$ is the total above ground biomass of the control treatment (fully irrigated treatment, $\mathrm{I}_{1}$ ), PARi $\mathrm{P}_{\mathrm{S}}$ and $\mathrm{PARi}_{\mathrm{C}}$ are the seasonal $\mathrm{PAR}_{\mathrm{i}}$ for the stress $\left(\mathrm{I}_{2}\right.$ to $\left.\mathrm{I}_{5}\right)$ and control treatments, respectively, and RUE $E_{S}$ and $R_{U} E_{C}$ are seasonal radiation use efficiencies for the stress and control treatments, respectively.

\section{Statistical Analysis}

Comparisons of growth parameters and resource use efficiencies among treatments were performed by analysis of variance in IBM SPSS, version 22 (IBM corp., NY, USA). Treatment means were separated using Duncan's Multiple Range Test (DMRT) and differences were considered statistically significant when $p<0.05$.

\section{RESULTS AND DISCUSSION}

\section{Crop phenological development}

Between years there was a slight difference in the time to a specific growth stage. In general, time to a specific growth stage was reached earlier during the 2014/15 season. Time, to the V6, V10, anthesis and physiological maturity growth stages was $25,33,60$, and 114 days after planting, respectively, in 2014/15. In the $2015 / 16$ season, the respective time to these growth stages were $30,39,71$, and 120 days after planting. The slightly earlier development in $2014 / 15$ can be attributed to the fairly warmer temperatures during early vegetative growth and the earlier onset of water stress leading to earlier plant maturity.

\section{Soil water availability and crop water stress}

At sowing the soil water content was close to FC in 2014/15, whereas in 2015/16 soil moisture at planting was slightly lower than FC at different soil profile depths (Fig. 2 ). Thus, irrigation scheduling based on a $40 \%$ soil water depletion in $I_{1}$ resulted in irrigation treatment application commencing earlier in the 2015/16 cropping season; 37 days after planting (DAP) compared to 41 DAP in 2014/15. Significantly higher rainfall during the 2015/16 cropping season resulted in a total of 5 irrigation applications compared to 8 in 2014/15. Total water applied during the 2014/15 season ranged from a high 555 $\mathrm{mm}$ in $\mathrm{I}_{1}$ to $235 \mathrm{~mm}$ for deficit treatment $\mathrm{I}_{5}$ (Table 1). In $2015 / 16, I_{1}$ received $375 \mathrm{~mm}$ of irrigation water while $I_{5}$ received $175 \mathrm{~mm}$. Given that only $40 \mathrm{~mm}$ of rainfall occurred during the 2014/15 cropping season, crop water consumption was dominated by irrigation water applied. Seasonal $\mathrm{ET}_{\mathrm{c}}$ estimated for the different irrigation levels for both cropping seasons is presented in Table 1.

For both seasons the SWC at harvest was lower than that at sowing for the different soil profile depths indicating that the crop extracted water from all soil layers (Fig. 2). However, most of the water was extracted from the upper soil layer $(0-60 \mathrm{~cm})$, and increasing water deficits resulted in greater depletion from the lower soil layers $(60-100 \mathrm{~cm})$. Further, there were significant differences $(p<0.05)$ in total soil water depleted among treatments in both years (Table 1). For both seasons, total soil water depleted between sowing and harvest storage was lower in treatments receiving more irrigation water. Soil water depletion between sowing and harvest was greater in 2014/15 than in 2015/16. This can be attributed to the increase in rainfall events occurring mid-season during the 2015/16 cropping season. 

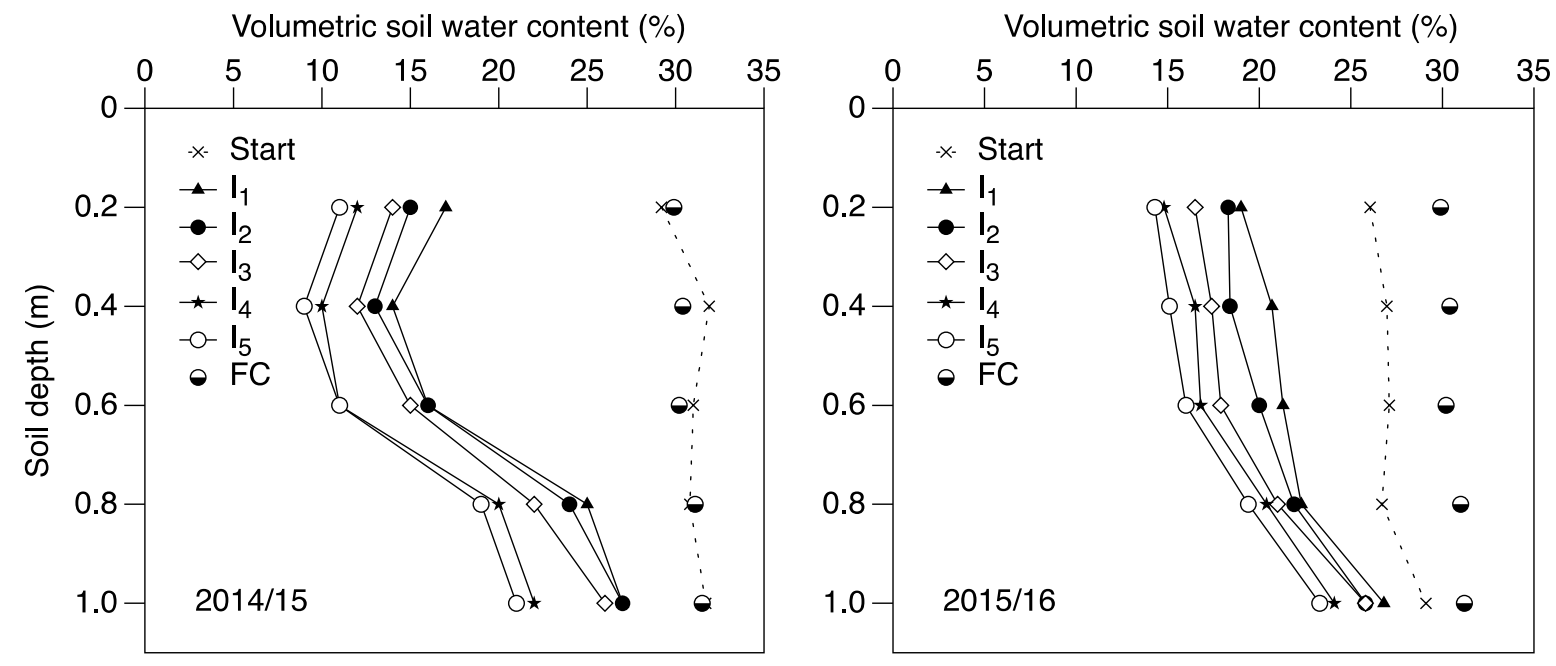

Figure 2. Volumetric soil water content at sowing (dashed line) and harvest (solid lines) at different soil depths for the different irrigation treatments. FC represents soil moisture at field capacity for the different profile depths.

Table 1. Cropping season total water applied, actual crop evapotranspiration $\left(\mathrm{ET}_{\mathrm{c}}\right)$ and total soil water depletion (SWD) for the $1 \mathrm{~m}$ root zone between sowing and harvest.

\begin{tabular}{|c|c|c|c|c|c|c|}
\hline \multirow{2}{*}{ Treatment } & \multicolumn{2}{|c|}{$\begin{array}{l}\text { Seasonal irrigation water } \\
(\mathbf{m m})\end{array}$} & \multicolumn{2}{|c|}{$\mathbf{E T}_{\mathbf{c}}(\mathbf{m m})$} & \multicolumn{2}{|c|}{ Total SWD (mm) } \\
\hline & $2014 / 15$ & $2015 / 16$ & $2014 / 15$ & $2015 / 16$ & $2014 / 15$ & $2015 / 16$ \\
\hline $\mathrm{I}_{1}$ & 555 & 375 & 605 & 570 & $64.39 \pm 1.32 \mathrm{a}$ & $43.67 \pm 0.54 \mathrm{a}$ \\
\hline $\mathrm{I}_{2}$ & 475 & 325 & 526 & 516 & $75.14 \pm 2.59 \mathrm{~b}$ & $57.26 \pm 1.22 \mathrm{~b}$ \\
\hline $\mathrm{I}_{3}$ & 395 & 275 & 455 & 464 & $89.56 \pm 2.75 \mathrm{c}$ & $71.91 \pm 3.73 \mathrm{c}$ \\
\hline $\mathrm{I}_{4}$ & 315 & 225 & 392 & 423 & $100.83 \pm 1.53 \mathrm{~d}$ & $81.45 \pm 0.83 \mathrm{~d}$ \\
\hline $\mathrm{I}_{5}$ & 235 & 175 & 331 & 352 & $107.53 \pm 2.07 \mathrm{~d}$ & $96.15 \pm 0.14 \mathrm{e}$ \\
\hline
\end{tabular}

According to Nielsen and Gardner (1987), the crop water stress index (CWSI) is closely related to extractable water in the root zone, making it an effective parameter for identifying the severity of crop water stress. For this study, the following threshold is adopted to indicate the severity of water stress imposed by the irrigation treatments: CWSI values $\leq 0.2$ little to no water stress, $0.2<\mathrm{CWSI}$ values $\leq 0.4$ mild to moderate water stress and CWSI $>0.4$ severe water stress. The threshold values adopted have been observed through literature review as being appropriate for the severity designated (Irmak et al., 2000; Candogan et al., 2013). For instance, evaluating the effects of irrigation scheduling based on various CWSI values on maize yield, Nielsen and Gardner (1987) reported insignificant reduction in yield when irrigating using 0.1 and 0.2 CWSI values, but a significant $(\alpha=0.05)$ reduction of 16 and $34 \%$ when irrigation was based on CWSI values of 0.4 and 0.6 , respectively. Similarly, Irmak et al. (2000) showed that a seasonal mean CWSI value $<0.2$ results in maximum maize yield production, while CWSI values exceeding 0.5 severely depressed yield and values of 0.28 and 0.36 moderately decreased yield by 12 and $24 \%$, respectively.

The different water depths caused varying levels of water stress among the treatments. Figure 3 shows the seasonal trend of CWSI for the different irrigation treatments. CWSI values were lower earlier in the season for all treatments and generally increased during the cropping season due to plant uptake, decreasing whenever irrigation water was applied and at significant rainfall events. During the 2015/16 growing season, rainfall totaling $59 \mathrm{~mm} 55$ to 57 DAP alleviated water stress in the soil profile reducing the need for irrigation, and frequent rainfall events between 57 and 70 DAP maintained a wet soil profile resulting in a slow increase in CWSI (Fig. 3). Varying water replenishment amount among the treatments resulted in marked differences in the progression of CWSI values. For treatments $\mathrm{I}_{4}$ and $\mathrm{I}_{5}$, crop water stress progressively increased, specifically during the reproductive growth stage, as irrigation failed to substantially reduce CWSI values since the water applied was not adequate to maintain a wet soil profile. Nielsen and Gardner (1987) and Irmak et al. (2002) reported similar observations in CWSI trend in cases of water deficit stress. Further, crops in $\mathrm{I}_{4}$ and $\mathrm{I}_{5}$ were exposed to water stress earlier than deficit treatments $I_{2}$ and $I_{3}$ during both seasons. During both cropping seasons, optimal growing conditions were maintained in $I_{1}$, the fully irrigated treatment, as indicated by the seasonal mean CWSI being 0.18 (2014/15) and 0.15 (2015/16) (Table 2). Treatments $I_{2}$ and $I_{3}$ with respective seasonal mean CWSI 
values of 0.23 and 0.29 across both years sustained mild to moderate water stress. Treatments $I_{4}$ and $I_{5}$ with mean CWSI values within range of 0.42 and 0.57 for both seasons incurred severe water stress. Further, during the reproductive growth stage, the stage that maize is most susceptible to water stress (Klocke et al., 2004), CWSI values indicated that crops in treatments $I_{2}$ and $I_{3}$ were subjected to mild levels of water stress while $\mathrm{I}_{4}$ and $\mathrm{I}_{5}$ experienced higher stress levels, particularly during the 2014/15 season (Table 2). Higher rainfall amounts in the $2015 / 16$ temporarily reducing the length of the drought cycle accounts for the lower CWSI observed during this growing season. Actual mean CWSI value at the time of

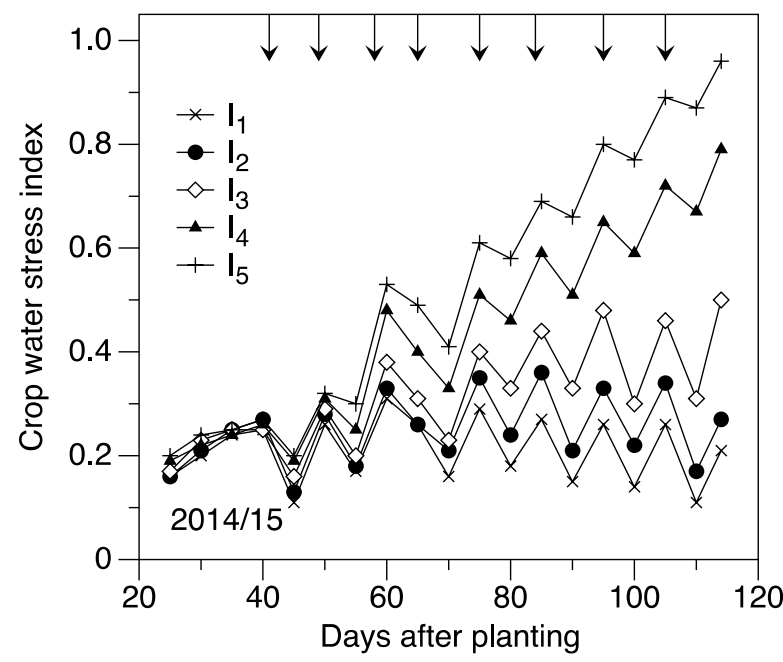

irrigation, representing $40 \%$ moisture depletion in $\mathrm{I}_{1}$, was 0.24 in $2014 / 15$ and 0.22 in 2015/16. Accordingly, a CWSI value of 0.23 could be taken as a threshold value to start irrigation for growing maize under optimal soil moisture conditions in similar environments. Candogan et al. (2013) observed that using CWSI values for irrigation scheduling is an effective and robust method, as it owns the advantage of representing both the soil and aerial environment. Results of the study also indicates that a threshold value of 0.45 for seasonal mean CWSI or 0.47 for CWSI before irrigation can be used to signify severe moisture stress and thus expectance of significant yield penalty and biomass reduction.

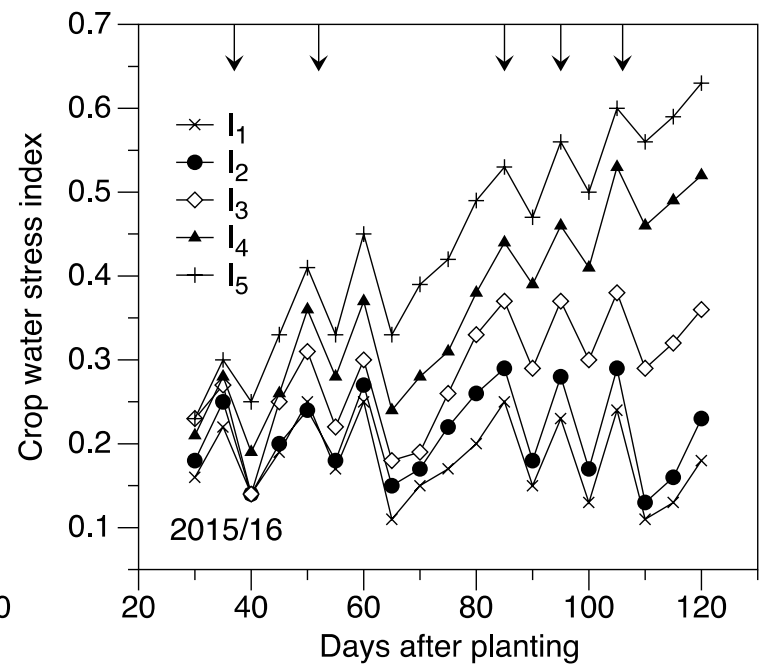

Figure 3. Seasonal variation in crop water stress index for the different irrigation treatments. Arrows at the top indicates irrigation events.

Table 2. Seasonal mean crop water stress index (CWSI), mean CWSI before irrigation and mean CWSI during the critical reproductive growth stage (RS) in 2014/15 and 2015/16.

\begin{tabular}{lllllll}
\hline \multirow{2}{*}{ Treat-ment } & \multicolumn{2}{l}{ Seasonal mean CWSI } & \multicolumn{2}{l}{ Mean CWSI during RS } & \multicolumn{2}{c}{ Mean CWSI before irrigation } \\
\cline { 2 - 7 } & $\mathbf{2 0 1 4 / 1 5}$ & $\mathbf{2 0 1 4 / 1 5}$ & $\mathbf{2 0 1 4 / 1 5}$ & $\mathbf{2 0 1 5 / 1 6}$ & $\mathbf{2 0 1 4 / 1 5}$ & $\mathbf{2 0 1 5 / 1 6}$ \\
\hline $\mathrm{I}_{1}$ & 0.18 & 0.19 & 0.19 & 0.22 & 0.24 & 0.22 \\
$\mathrm{I}_{2}$ & 0.25 & 0.27 & 0.27 & 0.27 & 0.32 & 0.27 \\
$\mathrm{I}_{3}$ & 0.34 & 0.39 & 0.39 & 0.34 & 0.39 & 0.34 \\
$\mathrm{I}_{4}$ & 0.48 & 0.59 & 0.59 & 0.44 & 0.49 & 0.44 \\
$\mathrm{I}_{5}$ & 0.57 & 0.71 & 0.71 & 0.56 & 0.62 & 0.56 \\
\hline
\end{tabular}

\section{Biomass accumulation and LAI}

The final above ground biomass observed at harvest varied among the different irrigation treatments (Table 3 ). In 2014/15, treatment $I_{1}$ produced the highest of $1774.05 \mathrm{~g}$ $\mathrm{m}^{-2}$ while $\mathrm{I}_{5}$ accumulated the lowest biomass of $1012.64 \mathrm{~g}$ $\mathrm{m}^{-2}$. In 2015/16 the highest and lowest total biomass was 1831.24 and $1175.52 \mathrm{~g} \mathrm{~m}^{-2}$ in $\mathrm{I}_{1}$ and $\mathrm{I}_{5}$, respectively. During both seasons there were significant differences in the total biomass accumulated among some treatments. In particular, for both seasons there was significant reduction in the biomass between $I_{1}$ and deficit treatments $I_{4}$ and $I_{5}$ within range of 27 and $43 \%$ for both years. The reduction in biomass was less than 9 and $20 \%$ in treatment $I_{2}$ and $I_{3}$, respectively. These findings are similar to those reported by Yazar et al. (1999) who observed that minimal biomass yield reductions occur at a threshold CWSI value of 0.33 or less for maize. Significant reductions in biomass owing to crop water stress have also been reported in other studies (Omidi et al., 2012; Djaman et al., 2013). The high productivity associated with DI in maize production, provided that water application amount is sufficient to maintain soil moisture below the stress threshold and irrigation timing does not impose stress doing the critical growth period, can be attributed to the stimulated physiological response of the crop after soil drying episodes leading to compensation or overcompensation in plant growth and grain yield (Yi et al., 2010). 
Table 3. Effects of irrigation treatments on final biomass at harvest and maximum leaf area index (LAI) at flowering.

\begin{tabular}{lll}
\hline Treatment & Biomass $\left(\mathbf{g ~ m}^{-\mathbf{2}}\right)$ & Max. LAI \\
\hline $\mathbf{2 0 1 4 / 1 5}$ & $1774.05 \pm 52.31 \mathrm{a}$ & $5.83 \pm 0.21 \mathrm{a}$ \\
$\mathrm{I}_{1}$ & $1613.02 \pm 65.46 \mathrm{a}$ & $5.47 \pm 0.16 \mathrm{a}$ \\
$\mathrm{I}_{2}$ & $1495.13 \pm 90.40 \mathrm{ab}$ & $4.87 \pm 0.05 \mathrm{~b}$ \\
$\mathrm{I}_{3}$ & $1290.24 \pm 30.50 \mathrm{bc}$ & $4.52 \pm 0.08 \mathrm{bc}$ \\
$\mathrm{I}_{4}$ & $1012.64 \pm 35.48 \mathrm{c}$ & $3.98 \pm 0.35 \mathrm{c}$ \\
$\mathrm{I}_{5}$ & & \\
$\mathbf{2 0 1 5 / 1 6}$ & $1831.24 \pm 11.60 \mathrm{a}$ & $6.05 \pm 0.15 \mathrm{a}$ \\
$\mathrm{I}_{1}$ & $1701.64 \pm 15.46 \mathrm{~b}$ & $5.51 \pm 0.14 \mathrm{~b}$ \\
$\mathrm{I}_{2}$ & $1462.51 \pm 30.22 \mathrm{c}$ & $5.01 \pm 0.06 \mathrm{c}$ \\
$\mathrm{I}_{3}$ & $1293.17 \pm 83.43 \mathrm{~d}$ & $4.61 \pm 0.05 \mathrm{~d}$ \\
$\mathrm{I}_{4}$ & $1175.52 \pm 27.57 \mathrm{~d}$ & $4.39 \pm 0.12 \mathrm{~d}$ \\
$\mathrm{I}_{5}$ & & \\
\hline Means \pm standard error of mean. Values followed by the same letter within a column for a given season are not significantly different $(p<0.05 ;$ MRT $)$
\end{tabular}

The seasonal evolution of LAI for the different irrigation treatments is depicted in Fig. 4. During early vegetative growth, LAI values were relatively close increasing considerably before maximizing during flowering. Following flowering, LAI values gradually decreased towards the end of the growing season. Soil water deficit caused notable variations in maximum LAI among irrigation treatments (Table 3). The maximum LAI of 5.83 was observed for treatment $\mathrm{I}_{1}$, with $\mathrm{I}_{2}, \mathrm{I}_{3}, \mathrm{I}_{4}$ and $\mathrm{I}_{5}$ respectively reducing their values by $6,17,22$ and $32 \%$ in $2014 / 15$. During the $2015 / 16$ cropping season, the relative reduction in maximum LAI for $\mathrm{I}_{2}, \mathrm{I}_{3}, \mathrm{I}_{4}$, and $\mathrm{I}_{5}$ compared to 6.05 in $I_{1}$ was $9,17,24$ and $27 \%$, respectively. The

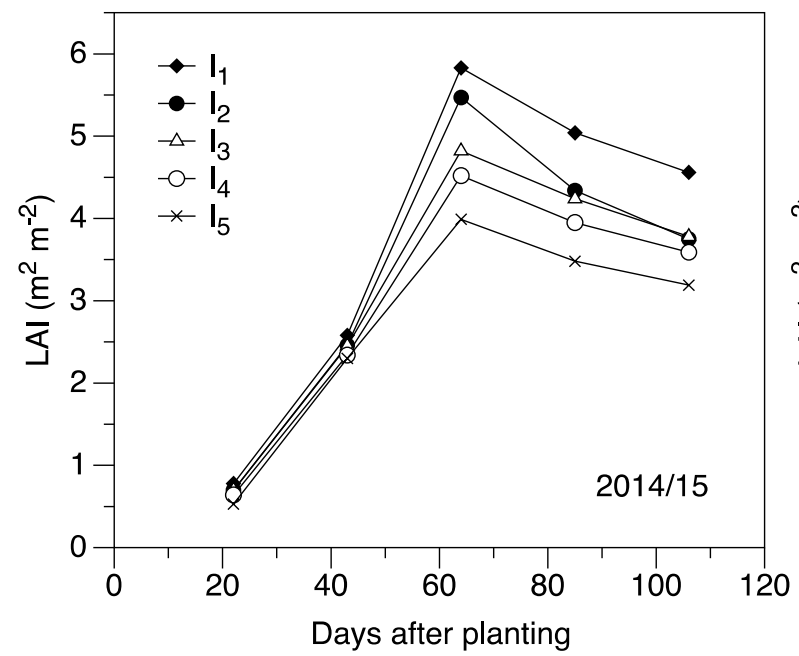

result of Duncan's significant testing on maximum LAI indicates that there were significant differences between the treatments (Table 3). This significant reduction in LAI relative to $I_{1}$ is a direct consequence of water stress incurred by these treatments. Farré and Faci (2009) noted that leaf expansion is usually the first plant phenological process to be affected by water stress. Observed LAI values were also greater during the 2015/16 cropping season than in 2014/15, which also recorded higher biomass accumulation at harvest, owing to the severity of water stress being less in this season.

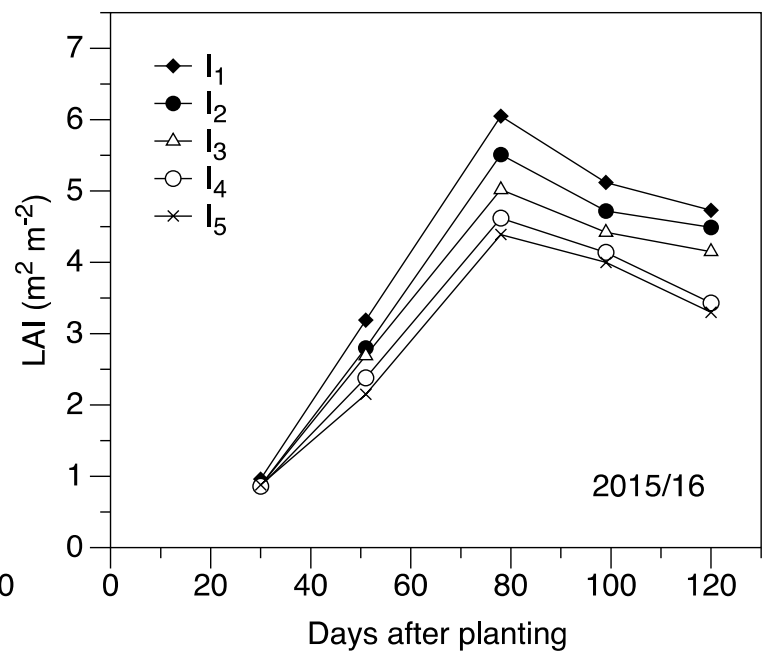

Figure 4. Seasonal variation in leaf area index (LAI) for the different treatments in both seasons.

\section{Effect of irrigation treatments on resource capture and use efficiencies}

As can be observed from Table 4, there were noticeable differences in the amount of $\mathrm{PAR}_{\mathrm{i}}$ among the different treatments and between seasons. The 2015/16 $\mathrm{PAR}_{\mathrm{i}}$ was consistently lower than in $2014 / 15$. This result observed can in part be attributed to the lower solar radiation recorded for this season as overcast and extensive cloud cover was more common owing to the prevailing wetter conditions. The different irrigation depths significantly influenced the total amount of PAR intercepted by the crop canopy in both years (Table 4). For the 2014/15 cropping season, the estimated $\mathrm{PAR}_{\mathrm{i}}$ among the treatments fell within the range of 484.32 to $531.65 \mathrm{MJ} \mathrm{m}^{-2}$. Similarly, during the 2015/16 cropping season there were significant reductions in $\mathrm{PAR}_{\mathrm{i}}$ for the deficit treatments within range of 4 to $8 \%$ relative to the $\mathrm{PAR}_{\mathrm{i}}$ in $\mathrm{I}_{1}$. The relatively higher cumulative $\mathrm{PAR}_{\mathrm{i}}$ 
recorded for treatment $I_{1}$ indicated that crops in this treatment utilized more energy than crops subjected to water deficits (Yi et al., 2010). The cumulative intercepted solar radiation observed for the full irrigation treatment in this study is lower than that reported in similar researches for maize, but the general trend of decreasing intercepted solar radiation with decreasing soil water availability is preserved (Yi et al., 2010; Teixeira et al., 2014). Further, the relative reduction in the amount of solar radiation intercepted owing to water stress have been reported in other studies for crops like bambara groundnut (Mwale et al., 2007), finger millet (Maqsood and Azam-Ali, 2007) and sweet sorghum (Dercas and Liakatas, 2007).

Table 4. Total photosynthetically active radiation intercepted $\left(\mathrm{PAR}_{\mathrm{i}}\right)$, seasonal radiation use efficiency (RUE) and seasonal mean and maximum crop growth rate (CGR) for the different irrigation treatments.

\begin{tabular}{|c|c|c|c|c|c|c|}
\hline \multirow{2}{*}{ Treatment } & \multirow{2}{*}{$\operatorname{PAR}_{\mathbf{i}}\left(\mathbf{M J ~ m}^{-\mathbf{2}}\right)$} & \multicolumn{3}{|l|}{ RUE } & \multicolumn{2}{|c|}{ CGR $\left(\mathrm{g} \mathrm{m}^{-2} \mathrm{~d}^{-1}\right)$} \\
\hline & & Slope $\left(\mathrm{g} \mathrm{MJ}^{-1}\right)$ & $\mathbf{R}^{2}$ & $\mathbf{P}^{\mathbf{a}}$ & Mean & Max. \\
\hline \multicolumn{7}{|l|}{$2014 / 15$} \\
\hline $\mathrm{I}_{1}$ & $531.65 \pm 2.74 \mathrm{a}$ & $3.41 \pm 0.01 \mathrm{a}$ & 0.89 & 0.02 & 16.94 & 33.03 \\
\hline $\mathrm{I}_{2}$ & $518.47 \pm 0.93 b$ & $3.21 \pm 0.08 \mathrm{~b}$ & 0.85 & 0.03 & 15.39 & 29.76 \\
\hline $\mathrm{I}_{3}$ & $512.97 \pm 1.32 \mathrm{~b}$ & $3.01 \pm 0.09 \mathrm{~b}$ & 0.80 & 0.04 & 14.31 & 25.82 \\
\hline $\mathrm{I}_{4}$ & $497.58 \pm 0.55 \mathrm{c}$ & $2.62 \pm 0.10 \mathrm{c}$ & 0.60 & 0.13 & 12.70 & 28.28 \\
\hline $\mathrm{I}_{5}$ & $484.36 \pm 2.20 \mathrm{~d}$ & $2.58 \pm 0.13 \mathrm{c}$ & 0.57 & 0.14 & 11.97 & 25.97 \\
\hline \multicolumn{7}{|l|}{$2015 / 16$} \\
\hline $\mathrm{I}_{1}$ & $443.71 \pm 2.67 \mathrm{a}$ & $3.51 \pm 0.02 \mathrm{a}$ & 0.81 & 0.04 & 20.84 & 34.12 \\
\hline $\mathrm{I}_{2}$ & $427.50 \pm 0.96 b$ & $3.22 \pm 0.16 \mathrm{~b}$ & 0.88 & 0.02 & 17.60 & 29.01 \\
\hline $\mathrm{I}_{3}$ & $421.37 \pm 2.54 \mathrm{c}$ & $3.08 \pm 0.05 \mathrm{~b}$ & 0.92 & 0.01 & 16.00 & 25.89 \\
\hline $\mathrm{I}_{4}$ & $413.04 \pm 0.90 \mathrm{~d}$ & $2.79 \pm 0.21 b c$ & 0.91 & 0.01 & 14.05 & 28.08 \\
\hline $\mathrm{I}_{5}$ & $407.11 \pm 1.78 \mathrm{e}$ & $2.69 \pm 0.16 \mathrm{c}$ & 0.79 & 0.04 & 12.34 & 29.08 \\
\hline
\end{tabular}

Means \pm standard error of mean. Values followed by the same letter within a column in a year are not significantly different $(p<0.05$; DMRT).

${ }^{\mathrm{a}} \mathrm{P}$ value of regression $(\alpha=0.05)$

In the fully irrigated treatment, $\mathrm{I}_{1}$, the $2014 / 15$ average seasonal crop growth rate (CGR) was $16.94 \mathrm{~g} \mathrm{~m}^{-2} \mathrm{~d}^{-1}$, with a range of 6 to $33 \mathrm{~g} \mathrm{~m}^{-2} \mathrm{~d}^{-1}$ between harvest intervals. In $2015 / 16$, the seasonal CGR for $\mathrm{I}_{1}$ was $20.84 \mathrm{~g} \mathrm{~m}^{-2} \mathrm{~d}^{-1}$ with a range of 9 to $34 \mathrm{~g} \mathrm{~m}^{-2} \mathrm{~d}^{-1}$ between harvest intervals. These ranges are within range of those reported in other studies under optimal growing conditions for maize (Lindquist et al., 2005). During both seasons, water stress reduced seasonal mean CGR for deficit treatments $\mathrm{I}_{2}$ to $\mathrm{I}_{4}$ with lower maximum values (Table 4). The CGR between successive harvest intervals was used to estimate maize RUE. That is, slope of the regression of CGR on rate of $\mathrm{PAR}_{\mathrm{i}}$ was used to estimate the RUE for the different irrigation treatments. The CGR method proved to be effective as small error variances were obtained for both seasons, and in general strong $\left(\mathrm{R}^{2}>0.80\right)$ and significant $(p<0.05)$ linear relations were-observed for most treatments (Table 4). According to Confalone et al. (2010), calculation of the RUE via the CGR method is less bias than the traditional cumulative biomass method owing to the independence between data sets which does not result in false confidence in the value of RUE. Some studies have also shown that there is no significant difference in RUE estimated through these two methods (Lindquist et al., 2005; Confalone et al., 2010).

Estimates of RUE varied marginally between years, and significantly between treatments for both season (Table 4). Results in the table show that the RUE decreased with decreasing water availability and thus increasing water stress. For instance, decreasing water application by $58 \%\left(\mathrm{I}_{1}\right.$ relative to $\mathrm{I}_{5}$ ) resulted in a significant 24\% reduction in RUE during the 2014/15 experimental period, while in 2015/16 a decrease of 53\% in irrigation water resulted in a significant reduction of $23 \%$ in RUE. In general however, during both cropping seasons the RUE was significantly different among the stress class distinctions. That is, significant testing indicated differences among crops grown under optimal water environments, moderate stress conditions and severe water stress conditions. Thus, all data was pooled in 3 categories to obtain a single estimate of the RUE under different water environments. Under optimal growing conditions, the seasonal RUE was estimated as $3.46 \pm$ $0.05 \mathrm{~g} \mathrm{MJ}^{-1}$. This value is similar to published values for maize (Kiniry et al., 1989; Yi et al., 2010). Regression analysis of pooled data showed that mild ( $I_{2}$ and $\left.I_{3}\right)$ and severe ( $\mathrm{I}_{4}$ and $\left.\mathrm{I}_{5}\right)$ water stress reduced the mean RUE to $3.11 \pm 0.12$ and $2.69 \pm 0.26 \mathrm{~g} \mathrm{MJ}^{-1}$, respectively. This reduction in RUE on account of soil moisture deficits is consistent with observations in other crops (Collino et al., 2001; Mwale et al., 2007). The RUE concept is utilized extensively in crop growth simulation models to predict crop growth and yield under different environments and management conditions (Brisson et al., 2003). Thus, as the results of this study indicate, varying water environments would affect plants RUE and the accuracy of models in simulating growth would be improved by considering this.

\section{Transpiration, soil evaporation and WUE}

The large difference in irrigation water application was sufficient to significantly affect $\mathrm{ET}_{\mathrm{c}}, \mathrm{W}_{\mathrm{t}}$, and the amount of water loss through evaporation $\left(\mathrm{E}_{\mathrm{cs}}\right)$ (Table 5). For both seasons, the amount of water loss through evaporation decreased with increasing soil moisture deficit. The range of reduction in $E_{c s}$ between the fully irrigated crop and 
those subjected to DI was 2 and $26 \%$. $\mathrm{E}_{\mathrm{cs}}$ accounted for 28 to $39 \%$ and 26 to $32 \%$ of $\mathrm{ET}_{\mathrm{c}}$ (Table 1) in $2014 / 15$ and $2015 / 16$, respectively. Similar to this study, Igbadun et al. (2008) reported a general decrease in surface evaporation for deficit irrigated maize compared to a fully irrigated treatment, with the average $\mathrm{E}_{\mathrm{cs}}$ percent of $\mathrm{ET}_{\mathrm{c}}$ in range of 28 to $35 \%$. In contrast, Mwale et al. (2007) reported a higher $\mathrm{E}_{\mathrm{cs}}$ percent claim on $\mathrm{ET}_{\mathrm{c}}$ for irrigated treatments compared to dryland treatments for bambara groundnut.
Soil evaporation is influenced by the wetness of the soil surface and the degree of ground cover by the crop canopy (Mwale et al., 2007; Igbadun et al., 2008). Thus, the higher $E_{c s}$ in treatment $I_{1}$ was perhaps dominated by the wetter soil surface over a longer time period although the crop canopy was more enhanced. As the soil dries up the effect of canopy cover on $E_{c s}$ diminishes since the moisture gradient between the atmosphere and the evaporating surface reduces (Mwale et al., 2007).

Table 5. Growing season total evaporation $\left(\mathrm{E}_{\mathrm{cs}}\right)$, transpiration $\left(\mathrm{W}_{\mathrm{t}}\right)$, and water use efficiency (WUE) for the different irrigation treatments.

\begin{tabular}{|c|c|c|c|c|c|}
\hline \multirow{2}{*}{ Treatment } & \multirow{2}{*}{$\mathbf{E}_{\mathrm{cs}}(\mathbf{m m})$} & \multirow{2}{*}{$\mathbf{W}_{\mathrm{t}}(\mathbf{m m})$} & \multicolumn{3}{|l|}{ WUE } \\
\hline & & & Slope $\left(\mathrm{g} \mathrm{m}^{-2} \mathrm{~mm}^{-1}\right)$ & $\mathbf{R}^{2}$ & $\mathbf{P}^{\mathbf{a}}$ \\
\hline \multicolumn{6}{|l|}{$2014 / 15$} \\
\hline $\mathrm{I}_{1}$ & $172.72 \pm 1.70 \mathrm{a}$ & $432.77 \pm 0.74 \mathrm{a}$ & $3.88 \pm 0.09 \mathrm{a}$ & 0.89 & 0.00 \\
\hline $\mathrm{I}_{2}$ & $169.53 \pm 0.37 \mathrm{a}$ & $356.23 \pm 0.37 \mathrm{~b}$ & $4.10 \pm 0.02 \mathrm{a}$ & 0.87 & 0.00 \\
\hline $\mathrm{I}_{3}$ & $168.26 \pm 0.39 \mathrm{a}$ & $286.35 \pm 1.31 \mathrm{c}$ & $4.85 \pm 0.04 \mathrm{~b}$ & 0.85 & 0.00 \\
\hline $\mathrm{I}_{4}$ & $151.02 \pm 4.36 \mathrm{~b}$ & $241.16 \pm 9.21 \mathrm{~d}$ & $5.10 \pm 0.10 \mathrm{c}$ & 0.77 & 0.01 \\
\hline $\mathrm{I}_{5}$ & $128.15 \pm 6.30 \mathrm{c}$ & $192.19 \pm 5.15 \mathrm{e}$ & $5.21 \pm 0.12 \mathrm{c}$ & 0.74 & 0.02 \\
\hline \multicolumn{6}{|l|}{$2015 / 16$} \\
\hline $\mathrm{I}_{1}$ & $149.28 \pm 0.64 \mathrm{a}$ & $420.87 \pm 1.12 \mathrm{a}$ & $4.08 \pm 0.00 \mathrm{a}$ & 0.91 & 0.00 \\
\hline $\mathrm{I}_{2}$ & $146.49 \pm 0.32 \mathrm{a}$ & $369.16 \pm 0.32 \mathrm{~b}$ & $4.13 \pm 0.12 \mathrm{a}$ & 0.90 & 0.00 \\
\hline $\mathrm{I}_{3}$ & $144.38 \pm 0.34 \mathrm{a}$ & $318.95 \pm 0.34 \mathrm{~b}$ & $4.62 \pm 0.01 \mathrm{~b}$ & 0.85 & 0.00 \\
\hline $\mathrm{I}_{4}$ & $131.50 \pm 3.68 b$ & $292.10 \pm 3.68 \mathrm{bc}$ & $4.48 \pm 0.05 \mathrm{~b}$ & 0.78 & 0.01 \\
\hline $\mathrm{I}_{5}$ & $111.56 \pm 5.38 \mathrm{c}$ & $241.27 \pm 4.03 \mathrm{c}$ & $4.59 \pm 0.07 \mathrm{~b}$ & 0.72 & 0.03 \\
\hline
\end{tabular}

The seasonal transpiration estimated for the different treatments is presented in Table 5. From the table it can be observed that $\mathrm{W}_{\mathrm{t}}$ decreased with a reduction in seasonal water applied for both seasons. The highest amount of water transpired was observed in $\mathrm{I}_{1}$ while the least was recorded in deficit treatment $\mathrm{I}_{5}$. $\mathrm{W}_{\mathrm{t}}$ between the fully irrigated crop and deficit treatments decreased with increasing soil water deficits within range 18 to $56 \%$ in $2014 / 15$ and 12 to $43 \%$ in 2015/16. Owing to the marked differences in water applied to the different treatments and hence seasonal $\mathrm{ET}_{\mathrm{c}}, \mathrm{W}_{\mathrm{t}}$ was significantly different among all treatments. This reduction in transpiration with decreasing soil moisture availability suggest that crops reduce their water losses by closing their stomata in water stress environments, supporting the findings of other studies (Mwale et al., 2007; Ashraf et al., 2016). Ashraf et al. (2016) reported that water stress induces stomatal closure that leads to a reduced working efficiency of photosynthetic machinery and crop transpiration rates, which ultimately leads to a reduction in maize productivity. The differences in $\mathrm{W}_{\mathrm{t}}$ therefore impacted the WUE which varied significantly among treatments (Table 5). Results in the table shows that generally the WUE increased with decreasing water application. In 2014/15 the WUE was significantly higher in $\mathrm{I}_{4}$ and $\mathrm{I}_{5}$ compared to the other treatments. A reduction of $58 \%$ in irrigation application improved plant WUE by $25 \%$ ( $\mathrm{I}_{5}$ compared to $I_{1}$ ). During the $2015 / 16$ growing season, the improvement in the WUE as a result of water deficits was smaller; the highest increase being $12 \%$ in $\mathrm{I}_{3}$ followed by 11 and $9 \%$ in $\mathrm{I}_{5}$ and $\mathrm{I}_{4}$, respectively. The relative difference in the improvement between seasons is largely due to the much drier conditions during the 2014/15 growing season. Teixeira et al. (2014) also reported greater transpiration WUE's for maize subjected to water stress.

\section{Effect of radiation capture and use efficiency on biomass reduction}

Table 6 shows the estimated biomass reduction component relative to $\mathrm{I}_{1}$ for the different irrigation treatments attributable to reductions in $\mathrm{PAR}_{\mathrm{i}}$ and RUE in each year. Reduced $\mathrm{PAR}_{\mathrm{i}}$ produced the smallest yield loss component for each treatment in both seasons, and the magnitude was more pronounced in the severely stressed treatments of $\mathrm{I}_{4}$ and $\mathrm{I}_{5}$ in each year. Stone et al. (2001) and Earl and Davis (2003) also reported that in severely stressed water environments reduced radiation interception plays an important part in yield loss. The reduction in biomass owing to reduced RUE was markedly higher than the reduction caused by a decrease in $\mathrm{PAR}_{\mathrm{i}}$. Similar to the findings of Earl and Davis (2003), the results suggest that reduced RUE was quantitatively more important than reduced $\mathrm{PAR}_{\mathrm{i}}$ in terms of the effects on biomass loss (Table 6), and it significantly affects biomass production. This has important implications as it suggest that the relatively low radiation during the winter cropping season affects maize growth and productivity during this cropping period. Therefore, perhaps DI as a water management strategy may have greater benefits if maize is grown in more conducive aerial environments. Experiments exploring different planting dates would be valuable. 


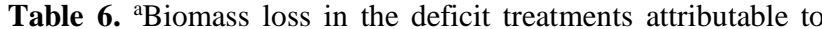
reduced intercepted photosynthetically active radiation $\left(\mathrm{PAR}_{\mathrm{i}}\right)$ and reduced radiation use efficiency (RUE).

\begin{tabular}{lll}
\hline Treatment & PAR $_{\mathbf{i}}$ & RUE \\
\hline $2014 / 15$ & & $\%$ \\
$\mathrm{I}_{2}$ & $3.04 \pm 0.15 \mathrm{a}$ & $6.12 \pm 1.00 \mathrm{a}$ \\
$\mathrm{I}_{3}$ & $4.23 \pm 0.71 \mathrm{a}$ & $11.66 \pm 0.53 \mathrm{a}$ \\
$\mathrm{I}_{4}$ & $6.41 \pm 0.42 \mathrm{~b}$ & $23.28 \pm 2.62 \mathrm{~b}$ \\
$\mathrm{I}_{5}$ & $8.89 \pm 0.37 \mathrm{c}$ & $24.18 \pm 2.70 \mathrm{~b}$ \\
$2015 / 16$ & & \\
$\mathrm{I}_{2}$ & $3.65 \pm 0.40 \mathrm{a}$ & $8.97 \pm 1.16 \mathrm{a}$ \\
$\mathrm{I}_{3}$ & $5.04 \pm 0.54 \mathrm{a}$ & $11.18 \pm 1.43 \mathrm{a}$ \\
$\mathrm{I}_{4}$ & $6.91 \pm 0.37 \mathrm{~b}$ & $20.02 \pm 3.78 \mathrm{ab}$ \\
$\mathrm{I}_{5}$ & $8.27 \pm 0.41 \mathrm{~b}$ & $24.85 \pm 4.58 \mathrm{~b}$ \\
\hline
\end{tabular}

Means \pm standard error of mean. Values followed by the same letter within a column in a year are not significantly different $(p<0.05$; DMRT)

${ }^{\text {a }}$ Values are presented as a percent of the maximum biomass in the fully irrigated treatment

\section{CONCLUSION}

Understanding the effect of optimal and limiting water environments on resource capture and use efficiencies can aid in sustainable agricultural development since they can be used to predict plant dry matter accumulation and grain yield. The results show that water stress has significant impacts on the capture of light and water and the conversion of these resources into biological yield in maize. Under water stress the amount of PAR intercepted significantly decreased as a consequence of reduced LAI. In addition, crop water stress significantly reduced the RUE within range of 5.9 and $24.3 \%$ relative to the RUE observed under optimal soil moisture environments. The reduction of both $\mathrm{PAR}_{\mathrm{i}}$ and RUE was an important limitation to the amount of final above ground biomass produced. Although soil water deficits reduced the final biomass both through a reduction in radiation interception and conversion efficiency, it translated into higher efficiency of water use. The results of this study suggest that in mild water stress environments the relatively high productivity of the maize crop was strongly influenced by high RUE, and in cases of severe water stress, the reduced ability to capture and utilize solar radiation is compensated by improving the WUE.

\section{LITERATURE CITED}

Akcay, S. and N. Dagdelen. 2016. Water use efficiency, yield and yield components of second crop sunflower under deficit irrigation. Turk J Field Crops. 21:190-199.

Albrizio, R. and P. Steduto. 2005. Resource use efficiency of field-grown sunflower, sorghum, wheat and chickpea I. Radiation use efficiency. Agric. For. Meteorol. 130:254-268.

Alderfasi, A.A. and D.C. Nielsen. 2001. Use of crop water stress index for monitoring water status and scheduling irrigation in wheat. Agric. Water Manag. 47:69-75.

Ashraf, U., M.N. Salim, A. Sher, S.R. Sabir, A. Khan, S. Pan and X. Tang. 2016. Maize growth, yield formation and water- nitrogen usage in response to varied irrigation and nitrogen supply under semi-arid climate. Turk J. Field Crops 21:88-96.

Brisson, N., C. Gary, E. Justes, R. Roche, B. Mary, D. Ripoche, D. Zimmer, J. Sierra, P. Bertuzzi, P. Burger, F. Bussière, Y.M. Cabidoche, P. Cellier, P. Debaeke, J.P. Gaudillère, C.
Hénault, F. Maraux, B. Seguin and H. Sinoquet. 2003. An overview of the crop model STICS. Eur. J. Agron. 18:309332.

Candogan, B.N., M. Sincik, H. Buyukcangaz, C. Demirtas, A.T. Goksoy and S. Yazgan. 2013. Yield, quality and crop water stress index relationships for deficit-irrigated soybean [Glycine max (L.) Merr.] in sub-humid climatic conditions. Agric. Water Manag. 118:113-121.

Collino, D.J., J.L. Dardanelli, R. Sereno and R.W. Racca. 2001. Physiological responses of argentine peanut varieties to water stress. Light interception, radiation use efficiency and partitioning of assimilates. F. Crop. Res. 70:177-184.

Confalone, A., J.I. Lizaso, B. Ruiz-Nogueira, F.-X. LópezCedrón and F. Sau. 2010. Growth, PAR use efficiency, and yield components of field-grown Vicia faba $L$. under different temperature and photoperiod regimes. F. Crop. Res. 115:140-148.

Demetriades-Shaw, T.H., M. Fuchs, E.T. Kanemasu and I. Flitcroft. 1994. Further discussions on the relationship between cumulated intercepted solar radiation and crop growth. Agric. For. Meteorol. 68:231-242.

Dercas, N. and A. Liakatas. 2007. Water and radiation effect on sweet sorghum productivity. Water Resour. Manag. 21:1585-1600.

Djaman, K., S. Irmak, W.R. Rathje, D.L. Martin and D.E. Eisenhauer. 2013. Maize evapotranspiration, yield production functions, biomass, grain yield, harvest index, and yield response factors under full and limited irrigation. Am. Soc. Agric. Biol. Eng. 56:273-293.

Earl, H.J. and R.F. Davis. 2003. Effect of drought stress on leaf and whole canopy radiation use efficiency and yield of maize. Agron. J. 95:688-696.

Farré, I. and J.-M. Faci. 2009. Deficit irrigation in maize for reducing agricultural water use in a Mediterranean environment. Agric. Water Manag. 96:383-394.

Idso, S.B. 1982. Non-water-stressed baselines: a key to measuring and interpreting plant water stress. Agric. Meterology 27:59-70.

Igbadun, H.E., B.A. Salim, A.K.P.R. Tarimo and H.F. Mahoo. 2008. Effects of deficit irrigation scheduling on yields and soil water balance of irrigated maize. Irrig. Sci. 27:11-23.

Irmak, A., W.D. Batchelor, J.W. Jones, S. Irmak, J.O. Paz, H.W. Beck and M. Egeh. 2002. Relationship between plant available soil water and yield for explaining soybean yield variability. Appl. Eng. Agric. 18:471-482.

Irmak, S., D.Z. Haman and R. Bastug. 2000. Determination of crop water stress index for irrigation timing and yield estimation of corn. Agron. J. 92:1221-1227.

Jackson, R.D. 1982. Canopy temperature and crop water stress. p. 43-85. In Hillel, D. (ed.), Advances in Irrigation. Volume 1. Academic Press, New York.

Kiniry, J.R., C.A. Jones, J.C. O'toole, R. Blanchet, M. Cabelguenne and D.A. Spanel. 1989. Radiation-use efficiency in biomass accumulation prior to grain-filling for five grain-crop species. F. Crop. Res. 20:51-65.

Klocke, N.L., J.P. Schneekloth, S.R. Melvin, R.T. Clark and J.O. Payero. 2004. Field scale limited irrigation scenarios for water policy strategies. Appl. Eng. Agric. 20:623-631.

Kuscu, H., A. Karasu, M. Oz, A.O. Demir and I. Turgut. 2013. Effect of irrigation amounts applied with drip irrigation on maize evapotranspiration, yield, water use efficiency, and net return in a sub-humid climate. Turk J Field Crops. 18:13-19.

Lindquist, J.L., T.J. Arkebauer, D.T. Walters, K.G. Cassman and A. Dobermann. 2005. Maize radiation use efficiency under optimal growth conditions. Agron. J. 97:72-78.

Maqsood, M. and S.N. Azam-Ali. 2007. Effects of drought on growth, development, radiation use efficiency and yield of 
finger millet (Eleucine coracana). Pakistan J. Bot. 39:123134.

Mwale, S.S., S.N. Azam-Ali and F.J. Massawe. 2007. Growth and development of bambara groundnut (Vigna subterranea) in response to soil moisture 2. Resource capture and conversion. Eur. J. Agron. 26:354-362.

Nielsen, D.C. and B.R. Gardner. 1987. Scheduling irrigations for corn with the crop water stress index (CWSI). Appl. Agric. Res. 2:295-300.

O'Connell, M.G., G.J. O'Leary, D.M. Whitfield and D.J. Connor. 2004. Interception of photosynthetically active radiation and radiation-use efficiency of wheat, field pea and mustard in a semi-arid environment. F. Crop. Res. 85:111-124.

Omidi, A.H., Khazaei, H., Monneveux, P. and F. Stoddard. 2012. Effect of cultivar and water regime on yield and yield components in safflower (Carthamus tinctorius L.). Turkish J. F. Crop. 17:10-15

Panda, R.K., S.K. Behera and P.S. Kashyap. 2004. Effective management of irrigation water for maize under stressed conditions. Agric. Water Manag. 66:181-203.

Payero, J.O., N.L. Klocke, J.P. Schneekloth and D.R. Davison. 2006. Comparison of irrigation strategies for surfaceirrigated corn in West Central Nebraska. Irrig. Sci. 24:257265.

Perng, C.M. 2013. Taiwan Grain and Feed Annual Wheat, Corn and Milled Rice Situation and Outlook. Taipei, Taiwan.

Rahman, M.M. and M.M. Hossain. 2011. Plant density effects on growth, yield and yield components of two soybean varieties under equidistant planting arrangement. Asian J. Plant Sci. 10:278-286.

Ritchie, S.W., J.J. Hanway and G.O. Benson. 1992. How a corn plant develops. Ames, Iowa.

Sinclair, T.R., and R.C. Muchow. 1999. Radiation use efficiency. Adv. Agron. 65: 215-265.

Spiertz, H. 2012. Avenues to meet food security. The role of agronomy on solving complexity in food production and resource use. Eur. J. Agron. 43:1-8.

Steduto, P. and R. Albrizio. 2005. Resource use efficiency of field-grown sunflower,sorghum, wheat and chickpea II. Water use efficiency and comparison with radiation use efficiency. Agric. For. Meteorol. 130:269-281.

Stone, P.J., D.R. Wilson, J.B. Reid and R.N. Gillespie. 2001. Water deficit effects on sweet corn. I. Water use, radiation use efficiency, growth, and yield. Aust. J. Agric. Res. 52:103-113.

Teixeira, E.I., M. George, T. Herreman, H. Brown, A. Fletcher, E. Chakwizira, J. De Ruiter, S. Maley and A. Noble. 2014. The impact of water and nitrogen limitation on maize biomass and resource-use efficiencies for radiation, water and nitrogen. F. Crop. Res. 168:109-118.

Vadez, V., J. Kholova, S. Medina, A. Kakkera and H. Anderberg. 2014. Transpiration efficiency: new insights into an old story. J. Exp. Bot. 65:6141-6153.

Yazar, A., A.T. Howell, A.D. Dusek and S.K. Copeland. 1999. Evaluation of crop water stress index for LEPA irrigated corn. Irrig. Sci. 18:171-180.

Yi, L., Y. Shenjiao, L. Shiqing, C. Xinping and C. Fang. 2010. Growth and development of maize (Zea mays L.) in response to different field water management practices: Resource capture and use efficiency. Agric. For. Meteorol. 150:606613. 